\title{
Alternative Pathway is Involved in Nitric Oxide-Enhanced Tolerance to Cadmium Stress in Barley Roots
}

\author{
Li He ${ }^{1}$, Xiaomin Wang ${ }^{1,2}$, Ruijun Feng ${ }^{1}$, Qiang He ${ }^{1}$, Shengwang Wang ${ }^{1}$, Cuifang Liang ${ }^{1}$, \\ Lili Yan ${ }^{1}$ and Yurong Bi ${ }^{1, *}$ \\ 1 Ministry of Education Key Laboratory of Cell Activities and Stress Adaptations, School of Life Sciences, \\ Lanzhou University, Lanzhou, Gansu 730000, China; hel16@1zu.edu.cn (L.H.); \\ wangxiaomin@lzu.edu.cn (X.W.); fengrj16@lzu.edu.cn (R.F.); heq15@lzu.edu.cn (Q.H.); \\ wangshw16@lzu.edu.cn (S.W.); liangcf16@lzu.edu.cn (C.L.); yanll18@lzu.edu.cn (L.Y.) \\ 2 State Key Laboratory of Plateau Ecology and Agriculture, Qinghai University, Xining, Qinghai 810016, China \\ * Correspondence: yrbi@lzu.edu.cn; Tel.: +86-931-8911781
}

Received: 11 October 2019; Accepted: 25 November 2019; Published: 29 November 2019

check for updates

\begin{abstract}
Alternative pathway (AP) has been widely accepted to be involved in enhancing tolerance to various environmental stresses. In this study, the role of AP in response to cadmium (Cd) stress in two barley varieties, highland barley (Kunlun14) and barley (Ganpi6), was investigated. Results showed that the malondialdehyde (MDA) content and electrolyte leakage (EL) level under Cd stress increased in two barley varieties. The expressions of alternative oxidase $(A O X)$ genes (mainly $A O X 1 a)$, AP capacity $\left(\mathrm{V}_{\text {alt }}\right)$, and AOX protein amount were clearly induced more in Kunlun14 under $\mathrm{Cd}$ stress, and these parameters were further enhanced by applying sodium nitroprussid (SNP, a $\mathrm{NO}$ donor). Moreover, $\mathrm{H}_{2} \mathrm{O}_{2}$ and $\mathrm{O}_{2}{ }^{-}$contents were raised in the $\mathrm{Cd}$-treated roots of two barley varieties, but they were markedly relieved by exogenous SNP. However, this mitigating effect was aggravated by salicylhydroxamic acid (SHAM, an AOX inhibitor), suggesting that AP contributes to NO-enhanced Cd stress tolerance. Further study demonstrated that the effect of SHAM application on reactive oxygen species (ROS)-related scavenging enzymes and antioxidants was minimal. These observations showed that AP exerts an indispensable function in NO-enhanced Cd stress tolerance in two barley varieties. AP was mainly responsible for regulating the ROS accumulation to maintain the homeostasis of redox state.
\end{abstract}

Keywords: alternative pathway; Cd stress; nitric oxide; reactive oxygen species

\section{Introduction}

Cadmium $(\mathrm{Cd})$, one of the most toxic heavy metals to the environment, has drawn great attention worldwide. It not only inhibits plant growth, but also pollutes the food chain, seriously threatening human health [1,2]. When $\mathrm{Cd}$ is accumulated excessively, at the physiological level, a suite of symptoms, such as chlorosis, underdevelopment, and programmed cell death, are induced in plants [3-5]. At the cellular level, over-accumulated $\mathrm{Cd}$ affects enzyme activity and changes protein structure [4,6,7]. More importantly, cellular redox homoeostasis is disturbed, and reactive oxygen species (ROS) burst, which further leads to oxidative stresses. To better deal with $\mathrm{Cd}$ toxicity, plants have evolved various defense strategies. Activating antioxidant enzymes and non-enzymatic antioxidants to counteract the oxidative stress has been widely accepted [8,9]. Alternative pathway (AP) also contributes to enhancing Cd tolerance [10]. Even though great effort has been made in the past, the protective mechanisms against Cd stress still need to be explored. 
Nitric oxide (NO), known as a multifunctional signaling molecule, has been widely reported upon in recent years. It not only functions in plant physiological processes, but also defends against various environmental stresses [11-13], even mitigating heavy metal toxicity [14,15]. There are enzymatic and non-enzymatic systems that produce NO [16,17]. Increasing findings on defensive roles of $\mathrm{NO}$ to $\mathrm{Cd}$ toxicity have been widely reported. At the cellular level, to reduce $\mathrm{Cd}$-induced ROS over-accumulation, $\mathrm{NO}$ enhances the antioxidant enzyme defense system among others [8,18-20]. At the molecular level, $\mathrm{NO}$, as a signaling molecule, enhances $\mathrm{Cd}$ stress response by cross-talking with auxin [21,22], abscisic acid [23], salicylic acid [24], polyamine [25], $\mathrm{Ca}^{2+}$ [25], and hydrogen sulfide [26], or by regulating protein kinase activities [27]. Although numerous studies have shown that NO could enhance Cd stress tolerance in different plants, there is little evidence to illuminate whether exogenous sodium nitroprussid (SNP; a NO donor) can improve Cd tolerance in highland barley.

Respiration has momentous functions in plant cell metabolism. Plant mitochondria possess a cyanide-resistant AP apart from the cyanide-sensitive cytochrome pathway (CP) [28]. Alternative oxidase (AOX), oriented in the mitochondria inner membrane, is a terminal oxidase of AP. When electrons flow to AOX, ROS production will markedly decrease, which helps hamper oxidative damages. When plants are exposed to low nitrogen stress, drought, and low temperature stresses, AP activity is obviously elevated [29-31]. Some findings have deemed that AP contributes to improving tolerance to various environmental stresses [32-34]. As outlined recently, NO can enhance AP to improve plant tolerance [35,36]. In consideration of lacking NO-related mutants, SNP has been widely used to mimic endogenous NO in the study of its various biological functions in plants [21,37]. Applying SNP upregulates the expression level of the AOX1a gene and the AOX activity in Arabidopsis [38]. NO is in charge of the expression activation of AOXla in tobacco [39]. Virus infection induces NO production, which might function as an upstream signal molecule to induce AP [35,36]. However, there is little evidence to confirm whether AP contributes to SNP-elevated tolerance to Cd stress in highland barley.

Highland barley, also known as naked barley, has been regarded as an excellent material to initiate mechanism study of crop tolerance to various stresses, as it generally grows in regions more than $3000 \mathrm{~m}$ above sea level where climate conditions are complicated and severe, including low temperature, high light intensity, and desolate soil, among other factors. In this study, three members ( $A O X 1 a, A O X 1 d 1$, and $A O X 1 d 2$ ) of the $A O X$ family were identified in highland barley. So far, there is little research that has studied the function of AOX in highland barley. In this study, we examined the response of AP to Cd stress in highland barley. Meanwhile, the function of NO in mediating AP under $\mathrm{Cd}$ stress was investigated. Moreover, the source of endogenous NO production was further clarified. The results indicated that AP plays an indispensable role in the SNP-enhanced Cd tolerance in highland barley by regulating the accumulation of ROS.

\section{Materials and Methods}

\subsection{Plant Materials and Growth Conditions}

Barley varieties Ganpi6 and Kunlun14 were used in the present study, and Ganpi6 was regarded as the control. Seeds were surface-disinfected with $2 \%$ hypochlorite for $8 \mathrm{~min}$, and washed thoroughly with sterile water. Then, seeds were transferred onto a nylon net on top of $200 \mathrm{~mL}$ plastic beakers (20 seedlings per beaker), which were filled with $1 / 4$-strengh modified culture solution [40]. Materials were allowed to grow in a chamber with $16 \mathrm{~h} \mathrm{light} / 8 \mathrm{~h}$ dark cycles. Culture solution was changed every 2 days. Different chemicals were added to the medium for various treatments after 6 days. Roots were utilized immediately for the following assays. 


\subsection{Root Elongation Measurement}

After 6 day growth, different concentrations of Cd were added to $200 \mathrm{~mL}$ 1/4-strengh modified Johnsons nutrient solution for $48 \mathrm{~h}$ [40]. The roots were collected immediately for measurement of root length with Image J.

\subsection{Root Electrolyte Leakage Determination}

Electrolyte leakage (EL) was monitored according to the method described by Tang et al. (2014) [41]. First, $0.2 \mathrm{~g}$ roots were washed in the deionized water for more than three times. The roots were dipped in the deionized water for $2 \mathrm{~h}$ at $25^{\circ} \mathrm{C}$. The conductivity of the water bath $\left(\mathrm{C}_{1}\right)$ and the de-ionized water $\left(C_{0}\right)$ was measured. Root samples were then boiled at $100{ }^{\circ} \mathrm{C}$ for $40 \mathrm{~min}$, and the conductivity of the water bath $\left(\mathrm{C}_{2}\right)$ was measured when it cooled to room temperature.

\subsection{Malonaldehyde Content Determination}

Malondialdehyde (MDA) content was determined according to the methods described by Tang et al. (2014) [41] and Wang et al. (2012) [42]. Grinding $0.3 \mathrm{~g}$ roots in $2 \mathrm{~mL} \mathrm{10 \%} \mathrm{trichloroacetic} \mathrm{acid}$ (TCA) and centrifuging at 10,000 $\times g$ for $10 \mathrm{~min}$, the supernatant was then incubated with $1 \mathrm{~mL}$ TCA $(0.5 \%)$ at $95{ }^{\circ} \mathrm{C}$ for $30 \mathrm{~min}$, and centrifuged at $10,000 \times \mathrm{g}$ for $10 \mathrm{~min}$. The absorbance value was read at 532,440 , and $600 \mathrm{~nm}$.

\subsection{Measurements of Respiration Rate}

Respiration was measured on the basis of the method described by Wang et al. [43]. First, $0.03 \mathrm{~g}$ roots were cut into $2 \mathrm{~mm}$ small segments and put into $2 \mathrm{~mL} 50 \mathrm{mM}$ phosphate buffer (pH 6.8). After reaction for $2 \mathrm{~min}$ at room temperature, the oxygen value slope was defined as the total respiration rate $\left(\mathrm{V}_{\mathrm{t}}\right)$. Then, $2 \mathrm{mM} \mathrm{KCN}$ or $2 \mathrm{mM}$ salicylhydroxamic acid (SHAM) was added and reacted for $2 \mathrm{~min}$; the oxygen value slope was defined as the AP capacity $\left(\mathrm{V}_{\mathrm{alt}}\right)$ or the $\mathrm{CP}$ capacity $\left(\mathrm{V}_{\mathrm{cyt}}\right)$, independently.

\subsection{Determination of NO Content}

NO level was analyzed on the basis of the method described by Wang et al. [19]. Roots were bathed in the buffer containing [20 mM 4-amino-5-methylamino-2'7'-difluorofluorescein diacetate (DAF-FM-DA, NO fluorescent probe), $0.25 \mathrm{mM} \mathrm{NaCl}, 1 \mathrm{mM} \mathrm{CaCl}, 10 \mathrm{mM}$ Hepes-NaOH (pH 7.0)] for $30 \mathrm{~min}$. Then, roots were washed more than three times with $10 \mathrm{mM}$ Hepes-NaOH (pH 7.0)] buffer, and scanned in the Leica SM IRBE stereomicroscope. The images were analyzed by the Leica ZEN software.

\subsection{Determination of Nitrate Reductase (NR) Activity}

NR activity was measured following the method described by Mackintosh et al. [44]. First, $0.5 \mathrm{~g}$ roots were extracted in extract solution A containing $50 \mathrm{mM}$ Hepes- $\mathrm{KOH}$ (pH 7.5), 5\% glyceol, $1 \mathrm{mM}$ PMSF (Phenylmethanesulfonyl fluoride), $1 \mathrm{mM}$ dithiothreitol (DTT), $10 \mathrm{mM} \mathrm{MgCl}$, and $10 \mu \mathrm{M}$ FAD (flavin adenine dinucleotide). After being centrifuged at 15,000 $\times \mathrm{g}$ for $25 \mathrm{~min}, 250 \mu \mathrm{L}$ of supernatant was added to $250 \mu \mathrm{L}$ of reaction solution Hepes- $\mathrm{KOH}(\mathrm{pH} 7.5,50 \mathrm{mM}), \mathrm{KNO}_{3}(2 \mathrm{mM}), \mathrm{NADH}$ (reduced nicotinamide-adenine dinucleotid) $(0.2 \mathrm{mM})$, DTT (1 mM), $\left.\mathrm{MgCl}_{2}(10 \mathrm{mM})\right)$ and incubated for $15 \mathrm{~min}$. A total of $50 \mu \mathrm{L}$ of $0.5 \mathrm{M}$ zinc acetate was used to terminate the reaction. Following addition of $150 \mu \mathrm{L}$ of $1 \%$ sulfanilamide and $150 \mu \mathrm{L} 0.02 \%$ (w/v) $N$-(1-naphthy1) ethylenediamine dihydrochloride, the absorbance at $540 \mathrm{~nm}$ was recorded.

\subsection{Determination of Nitric Oxide Synthase (NOS) Activity}

NOS activity was measured according to the method described by Lin et al. [45]. First, $0.25 \mathrm{~g}$ roots were homogenized with $2 \mathrm{~mL}$ of extraction buffer and centrifuged at 15,000× $g$ for $15 \mathrm{~min}$. Then, $100 \mu \mathrm{L}$ of supernatant was added to the reaction solution, and $0.2 \mathrm{mM}$ NADPH (reduced nicotinamide adenine dinucleotide phosphate) was added to initiate the reaction. The absorbance at $340 \mathrm{~nm}$ was read. 


\subsection{Cloning, Sequencing, and Bioinformatics Analyses}

To obtain the intact open reading frame of $H v A O X 1$, primers (Table 1) were designed on the basis of $A O X$ sequence in highland barley roots. Genbank accession numbers were AK363239.1 (HvAOX1a), AK365405.1 (HvAOX1d1), and AK251266.1 (HvAOX1d2). A total of $15 \mu \mathrm{L}$ reaction mixture was used for PCR. The PCR conditions were $2 \mathrm{~min}$ at $98^{\circ} \mathrm{C}$, then 40 cycles of $20 \mathrm{sec}$ at $98^{\circ} \mathrm{C}, 30 \mathrm{sec}$ at $56.0-58.5^{\circ} \mathrm{C}$, $10 \mathrm{~min}$ at $72{ }^{\circ} \mathrm{C}$, and $10 \mathrm{~min}$ at $25^{\circ} \mathrm{C}$. The clear single target band was cloned to the pBlunt vector (TransGen Biotech, Beijing, China).

Table 1. Primer sequences.

\begin{tabular}{cc}
\hline Primer Name & Primer Sequence $\mathbf{( 5}^{\prime} \mathbf{- 3}^{\prime} \mathbf{)}$ \\
\hline Hvactin-F & GTGGTCGTACAACWGGTATTGTG \\
Hvactin-R & GCTCATCAAATCCAAACACTG \\
ORFHvAOX1a-F & GCAACGAACCTACAAGCGTG \\
ORFHvAOX1a-R & GCTAAAGAGCCCTCATTTCCTC \\
ORFHvAOX1d1-F & CCTCCCATTAGCTTTTCGACCAG \\
ORFHvAOX1d1-R & CGGTAGCACGTAACAGCGTGGACT \\
ORFHvAOX1d2-F & TACGACCACGAGTTTCGCGAGCA \\
ORFHvAOX1d2-R & GCTAAAGAGCCCTCATTTCCTC \\
qHvAOX1a-F & GCAACGAACCTACAAGCGTG \\
qHvAOX1a-R & AAGAGCCCAGCACCAACAA \\
qHvAOX1d1-F & CCTCCCATTAGCTTTTCGACCAG \\
qHvAOX1d1-R & CGGTAGCACGTAACAGCGTGGACT \\
qHvAOX1d2-F & TACGACCACGAGTTTCGCGAGCA \\
qHvAOX1d2-R & GCTAAAGAGCCCTCATTTCCTC \\
\hline
\end{tabular}

\subsection{RNA Isolation and $q R T-P C R$}

About $100 \mathrm{mg}$ samples were used for total RNA isolation from various plant tissues by using Trizol reagent. [cDNA synthesis kit (TRANS, Beijing, China)] was used for cDNA synthesis. The qRT-PCR mixture contained $5 \mu \mathrm{L}$ SYBR Green I Master Mix, $0.5 \mu \mathrm{L}$ forward primers, $0.5 \mu \mathrm{L}$ reverse primers, and $4 \mu \mathrm{L}$ deionized water. Each gene was amplified in three biological replicates. The results were analyzed by Rotor-Gene Real-Time Analysis Software 6.1. The specific primers are listed in Table 1.

\subsection{Western Blot Analysis}

Western blot analysis was carried out following the method described by Zhao et al. [46]. Proteins were separated on a $10 \%$ acrylamide gel. After electrophoresis, the proteins were transferred to a polyvinylidene difluoride membrane. The membrane was blocked for $3 \mathrm{~h}$ with $10 \%$ bovine serum albumin in buffer solution ( $150 \mathrm{mM} \mathrm{NaCl}, 0.05 \%$ Tween-20, $10 \mathrm{mM}$ Tris- $\mathrm{HCl}$ (pH8.0)). Primary antibody against Arabidopsis AOX was added and incubated for $10 \mathrm{~h}$. After rinsing three times, secondary antibody was added and incubated for visualization.

\subsection{2. $\mathrm{H}_{2} \mathrm{O}_{2}$ and $\mathrm{O}_{2}^{-}$Staining}

$\mathrm{H}_{2} \mathrm{O}_{2}$ and $\mathrm{O}_{2}{ }^{-}$staining was carried out according to the method described by Wang et al. [47]. Roots were stained in $0.5 \mathrm{mg} / \mathrm{mL}$ NBT (nitro blue tetrazolium) solution for $2 \mathrm{~h}$ or $2 \mathrm{mg} / \mathrm{mL}$ DAB (3,3-diaminobenzidine) solution for $12 \mathrm{~h}$, then de-stained in $95 \%$ ethanol for $40 \mathrm{~min}$. 


\subsection{Extraction and Estimation of Antioxidants}

First, $0.25 \mathrm{~g}$ fresh roots were ground in $2 \mathrm{~mL}$ meta-phosphoric acid (5\%) and centrifuged at $11,000 \times g$ for $20 \mathrm{~min}$, and then $1.0 \mathrm{U}$ ascorbate oxidase was added. The absorbance was read at $265 \mathrm{~nm}$. Oxidized ascorbate (DHA, dehydroascorbic acid) content was equal to the total ascorbic acid (AsA) content minus reduced AsA. Oxidized glutathione (GSSG) and reduced glutathione (GSH) contents were measured according to the method described by Giraud et al. [48].

\subsection{Antioxidant Enzyme Activity Assay}

First, $0.25 \mathrm{~g}$ fresh roots were ground in $3 \mathrm{~mL}$ pre-cooled $25 \mathrm{mM}$ Hepes buffers, and then were centrifuged at $4{ }^{\circ} \mathrm{C}$ for $20 \mathrm{~min}$ at $12,000 \times \mathrm{g}$. The supernatants were collected for examining the activity of antioxidant enzymes. SOD (Superoxide dismutase), CAT (Catalase), POD (Peroxidase) and APX (Ascorbate peroxidase) activities were measured on the basis of the method described by Jian et al. [36]. DHAR (Didehydroascorbic acid reductase), MDHAR (Monodehydroascorbic acid reductase), GR (Glutathione reductase), and GPX (Glutathione peroxidase) activities were measured following the method described by Zhang et al. [49].

\subsection{Statistical Analysis}

Each experiment was repeated at least three times with three replicates. The confidence coefficient was set at 0.05 . Experiments that required an analysis of variance were analyzed using SPSS 17.0 analysis of variance (ANOVA) and Origin 8.

\section{Results}

\subsection{Effects of Cd Stress on Dry Weight, Root Elongation, MDA Content, and EL}

$\mathrm{Cd}$ stress led to toxicity symptoms and inhibited the elongation of Ganpi6 and Kunlun14 roots in a dose-dependent manner. After exposure to various concentrations $(0-200 \mu \mathrm{M})$ of $C d$, the root growth of barley (Ganpi6) and highland barley (Kunlun14) was gradually inhibited (Figure 1A,B). Under $150 \mu \mathrm{M}$ Cd treatment, dry weight in Ganpi6 and Kunlun14 plants was reduced by $42.29 \%$ and $33.49 \%$, respectively (Figure 1C), whereas root elongation in Ganpi6 and Kunlun14 was decreased by $55.2 \%$ and $50.9 \%$, respectively (Figure 1D). To further explore the cellular membrane damage caused by Cd stress, two important indicators, MDA and EL levels, were examined. As shown in Figure 1E,F, the MDA content in Ganpi6 and Kunlun14 roots in the presence of $150 \mu \mathrm{M} \mathrm{Cd}$ was elevated 5.83-fold and 4.69-fold, respectively, whereas the EL was increased by $80.3 \%$ and $70.7 \%$, respectively. Thus, 150 $\mu \mathrm{M}$ Cd was selected for the subsequent assays. 


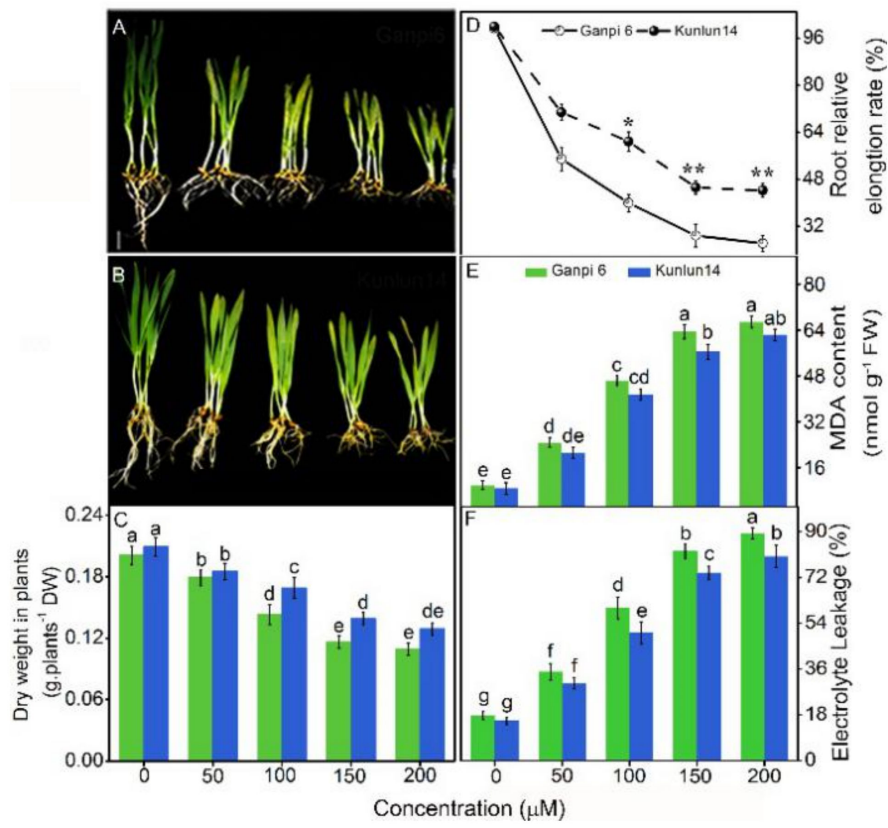

Figure 1. Effects of Cd on dry weight, root elongation, malondialdehyde (MDA), and electrolyte leakage (EL) in Ganpi6 and Kunlun14. (A) Growth of Ganpi6 seedlings under 0-200 $\mu \mathrm{M} \mathrm{Cd}$ treatment. (B) Growth of Kunlun14 seedlings under 0-200 $\mu \mathrm{M}$ Cd treatment. (C) Dry weight of Ganpi6 and Kunlun14 seedlings. (D) Root relative elongation (RRE) of Ganpi6 and Kunlun14 seedlings $(n>20)$. (E) MDA contents in Ganpi6 and Kunlun14 roots under 0-200 $\mu \mathrm{M}$ Cd treatment. (F) EL in Ganpi6 and Kunlun14 roots under 0-200 $\mu \mathrm{M}$ Cd treatment. Bar in $(\mathbf{A})=1 \mathrm{~cm}$. The six-day-old seedlings were grown in 1/4-strengh modified Johnson's nutrient solution with $0-200 \mu \mathrm{M} \mathrm{Cd}$ for $48 \mathrm{~h}$, and the primary root length, MDA contents, and EL were measured. Bars represent mean $\pm \mathrm{SE}(n=3)$. Different lower case letters represent significant difference at $p<0.05 ;{ }^{*}$ and ${ }^{* *}$ represent difference at $p<0.05$ and 0.01 , respectively.

\subsection{Effects of Cd Stress on the Respiratory Pathways}

To explore the response of respiration to $C d$ stress, $V_{t}, V_{\text {cyt }}$, and $V_{\text {alt }}$ in Ganpi6 and Kunlun14 were examined under various $C d$ concentrations. As shown in Figure $2 \mathrm{~A}, \mathrm{~V}_{\mathrm{t}}$ was rapidly increased when $\mathrm{Cd}$ concentration was lower than $150 \mu \mathrm{M}$, then it showed a declined trend. Compared with $\mathrm{V}_{\text {cyt }}$, $V_{\text {alt }}$ showed a similar pattern observed in $V_{t}$ under $C d$ stress (Figure $2 B, C$ ). It was noteworthy that $V_{\text {alt }}$, $\mathrm{V}_{\text {alt }} / \mathrm{V}_{\text {cyt }}$ were higher in Kunlun14 than those in Ganpi6 (Figure 2), suggesting that $\mathrm{V}_{\text {alt }}$ in Kunlun14 had a greater contribution to $\mathrm{V}_{\mathrm{t}}$ than Ganpi6 did under $\mathrm{Cd}$ stress. The time course of respiration changes under $150 \mu \mathrm{M} \mathrm{Cd}$ treatment were examined. The results showed that $V_{t}, V_{\text {alt }}$, and $V_{\text {cyt }}$ in both Ganpi6 and Kunlun14 reached their maximal values at $12 \mathrm{~h}$, followed by decreases. Nevertheless, all of them were still markedly higher than that in control roots (Figure 2E-G). 


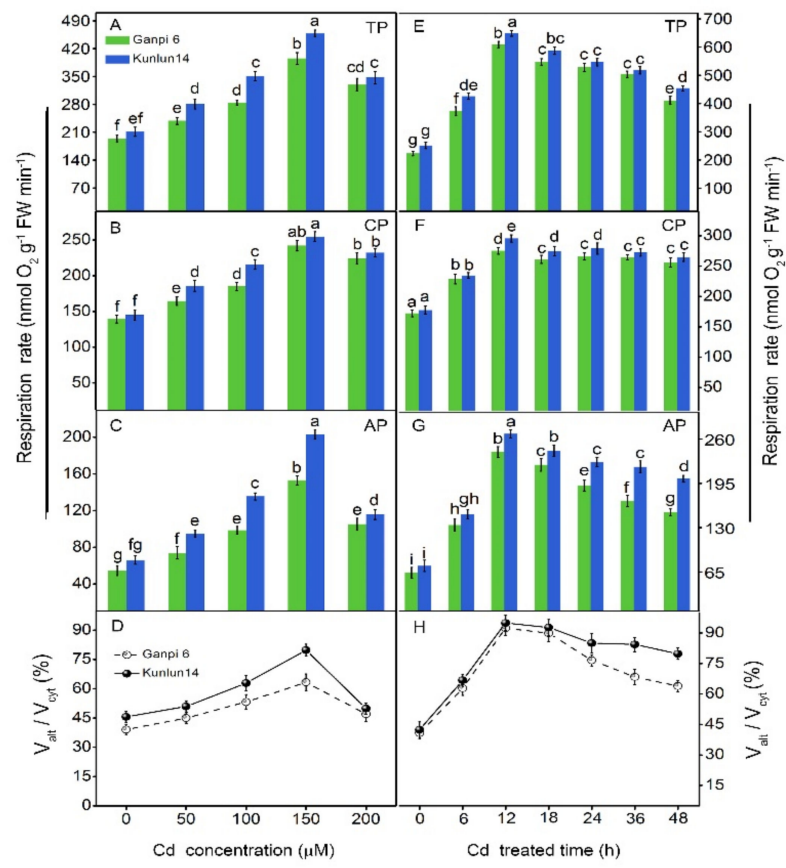

Figure 2. Effects of $\mathrm{Cd}$ on respiration rates in Ganpi6 and Kunlun14 roots. Changes of total respiration rate $(\mathrm{TP})(\mathrm{A})$, cytochrome respiration capacity $(\mathrm{CP})(\mathbf{B})$, alternative respiration capacity $(\mathrm{AP})(\mathrm{C})$ and Valt/Vcyt (D) under 0-200 $\mu \mathrm{M}$ Cd treatment for $48 \mathrm{~h}$. Changes of TP (E), CP (F), AP (G), and Valt/Vcyt (H) under $150 \mu \mathrm{M} \mathrm{Cd}$ treatment for different times. Ganpi6 and Kunlun14 seedlings were first grown in 1/4-strengh Johnson's nutrient solution. After 6 days of growth, seedlings were treated with 0-200 $\mu \mathrm{M}$ $\mathrm{Cd}$ for $48 \mathrm{~h}$. Bars represent mean $\pm \mathrm{SE}$ (standard deviation) $(\mathrm{n}=3)$ and different lower case letters represent significant difference at $p<0.05$.

\subsection{Cd Stress Induced NO Production from NR Pathway}

More and more evidence indicates that $\mathrm{NO}$ is involved in enhancing plant tolerance to $\mathrm{Cd}[50,51]$. To explore whether $\mathrm{Cd}$ stress excites NO release in Ganpi6 and Kunlun14, NO production was imaged by using DAF-FM, a fluorescent probe, together with NO donor (SNP) or scavenger (PTIO) treatment. In Ganpi6 and Kunlun14 roots, weak NO fluorescence signal was observed in control roots. However, $\mathrm{Cd}$ stress greatly enhanced the fluorescence signal, which was further intensified by SNP treatment (Figure 3A,B). Notably, the NO fluorescence signal was stronger in Kunlun14 than that in Ganpi6. Applying PTIO almost eliminated Cd-induced NO fluorescence signal (Figure 3A,B). To further explore the source of Cd-induced endogenous NO production in Ganpi6 and Kunlun14 roots, NR inhibitor $\left(\mathrm{NaN}_{3}\right)$ and NOS inhibitor (L-NNA) were used to detect NO original level. The results showed that $\mathrm{NaN}_{3}$ in Ganpi6 and Kunlun14 roots nearly abolished Cd-induced $\mathrm{NO}$ accumulation, whereas applying L-NNA had almost no impact on Cd-induced NO accumulation (Figure 3A), indicating that the Cd-induced NO production originated from the NR-dependent pathway. To further confirm this conclusion, NR and NOS activities were examined. Under Cd stress, NR activity in Ganpi6 and Kunlun 14 roots was increased by $57.6 \%$ and $72.1 \%$, respectively (Figure 3C). Furthermore, the NR activity showed a similar pattern as that of NO production (Figure 3B,C). However, the NOS activity had little change under Cd stress (Figure 3D).

Some studies reported that mitochondria might be an important source for NO generation via single electron leak from the electron transfer chain (ETC) to nitrite [52,53]. Moreover, recent studies have confirmed that AOX functions to protect ETC components from over-reduction in plants, thus preventing single electron leak [54]. To explore the link between NO and AP under Cd stress in Ganpi6 and Kunlun14 roots, SHAM (AOX inhibitor) was used to block the function of AP. As shown in Figure 3, under Cd + SHAM stress, NO fluorescence signal was strongly enhanced, suggesting that dysfunctional AP leads to over-reduction of ETC components. 

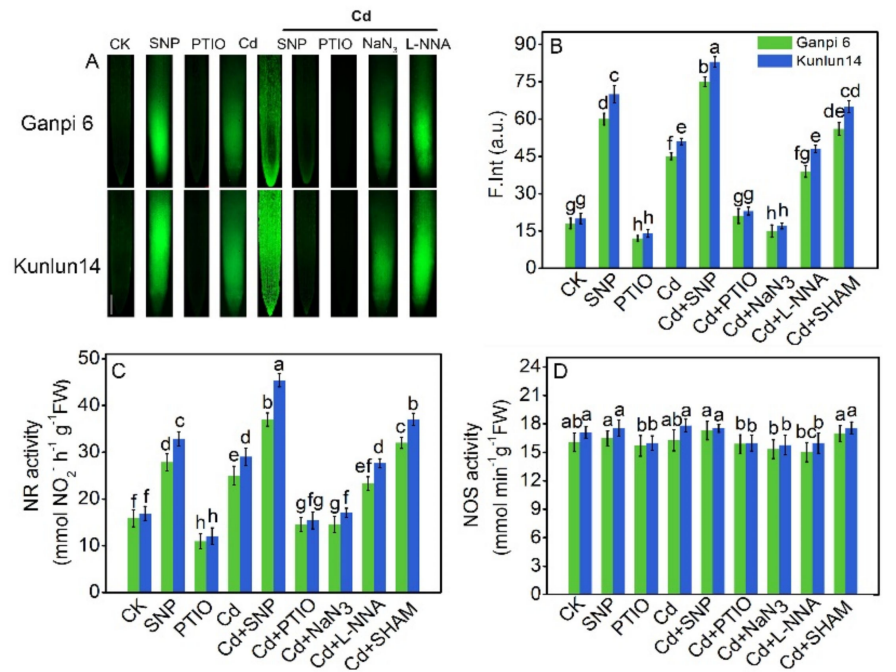

Figure 3. Effect of SNP (NO donor) on NO release. NO-dependent DAF-FM-DA (4-amino-5methylamino-2'7'-difluorofluorescein diacetate) fluorescence staining in Ganpi6 and Kunlun14 roots (A), quantification of NO fluorescence intensity (F. Int.) in the images in arbitrary units (a.u.) (B), nitrate reductase (NR) (C), and nitric oxide synthase (NOS) (D) activities under Cd stress in Ganpi6 and Kunlun14 roots. Bar $=1 \mathrm{~cm}$. In this experiment, $150 \mu \mathrm{M} \mathrm{Cd}, 150 \mu \mathrm{M}$ SNP, $25 \mu \mathrm{M}$ NaN3, $35 \mu \mathrm{M}$ NOS inhibitor (L-NNA), $100 \mu \mathrm{M}$ salicylhydroxamic acid (SHAM) were used. Bars represent mean $\pm \mathrm{SE}$ $(\mathrm{n}=3)$ and different lower case letters represent significant difference at $p<0.05$.

\subsection{Expression Patterns of AOX Genes in Highland Barley}

cDNA of $A O X$ was cloned from highland barley using the candidate gene approach [55]. Comparison with the nucleotide sequences to barley $A O X s$ confirmed that the highland barley $A O X s$ sequences were $A O X 1$ genes. These genes were named $H v A O X 1 a, H v A O X 1 d 1$, and $H v A O X 1 d 2$. The corresponding accession numbers were MK361118, MK361119, and MK361120. The transcript levels of HvAOX genes in different developmental stages of highland barley were analyzed using qRT-PCR. As shown in Figure 4, three HvAOX genes were detected in all tissues but with specific expression patterns. The expression of HvAOX1a was higher than that of HvAOX1d1 and HvAOX1d2 in all tissues except in stamens. It was worth mentioning that the transcript levels of $H v A O X s$ showed similar increasing pattern with the leaf age (from first leaves to function leaves), implying a common developmental-related feature of all $\mathrm{HvAOX}$ genes (Figure 4).

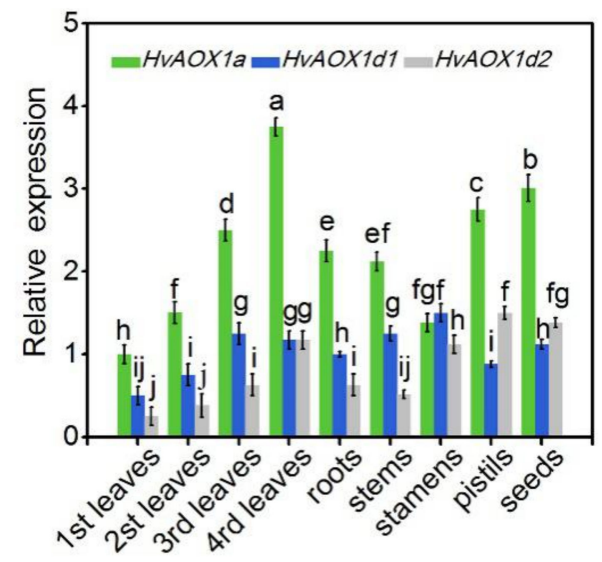

Figure 4. Relative expression of HvAOXs in Kunlun14. Different tissues of Kunlun14 were collected in the spring season. The relative transcript abundance was quantified by Rotor-Gene Real-Time Analysis Software 6.1. Bars represent mean \pm SE $(n=3)$. 


\subsection{Exogenous NO Enhanced HvAOX Expression in Ganpi6 and Kunlun14 Roots under Cd Stress}

AP usually runs at a low level, however, it could be observably induced when plants suffer from various environmental stresses [25]. To examine whether the increase of $\mathrm{V}_{\text {alt }}$ in Cd-stressed roots is regulated at the transcriptional level, $H v A O X$ expression was investigated. As shown in Figure 5, $H v A O X 1 a, H v A O X 1 d 1$, and $H v A O X 1 d 2$ in Ganpi6 and Kunlun14 were all expressed in roots. Compared with $H v A O X 1 d 1$ and $H v A O X 1 d 2$, the expression level of $H v A O X 1 a$ was markedly increased under $\mathrm{Cd}$ stress. To further explore how the expression levels of $H v A O X s$ were regulated in Cd-stressed roots, we manipulated the production of $\mathrm{NO}$ and monitored $\mathrm{HvAOXs}$ expression. Under $\mathrm{Cd}+\mathrm{SNP}$ treatment, the expression of $H v A O X 1 a$ was increased by 3.5 times and 4.4 times in Ganpi6 and Kunlun14 roots, respectively (Figure 5A), whereas $H v A O X 1 d 1$ and $H v A O X 1 d 2$ were just slightly increased (Figure 5B,C). Under Cd + SHAM treatment, the expression level of HvAOXs was dramatically reduced.

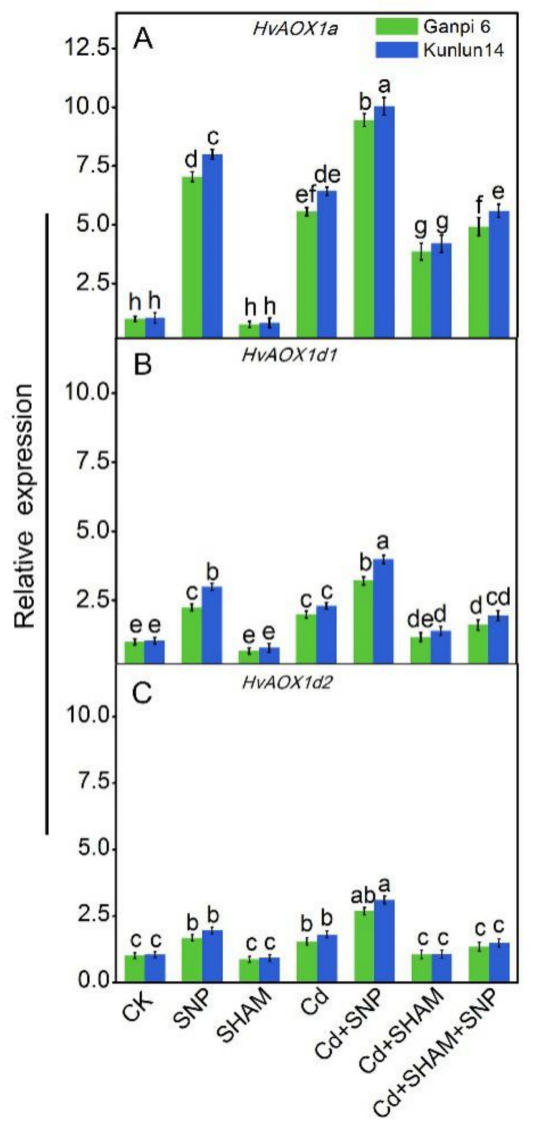

Figure 5. Effect of SNP and SHAM on the expression of HvAOX genes under Cd stress. HvAOX1a (A); HvAOX1d1 (B); HvAOX1d2 (C). In the experiment, $150 \mu \mathrm{M} \mathrm{Cd}, 150 \mu \mathrm{M}$ SNP, and $100 \mu \mathrm{M}$ SHAM were used. Bars represent mean $\pm \mathrm{SE}(n=3)$, and different lower case letters represent significant difference at $p<0.05$.

\subsection{Exogenous NO Enhanced $V_{\text {alt }}$ and AOX Protein Level under Cd Stress}

To further explore $\mathrm{NO}$ effects on respiration under $\mathrm{Cd}$ stress, $\mathrm{V}_{\text {alt }}$ and $\mathrm{V}_{\text {cyt }}$ were examined. As shown in Figure 6A, under Cd + SNP treatment, $V_{\text {alt }}$ in Ganpi6 and Kunlun14 roots was increased by $52.4 \%$ and $60.4 \%$, respectively, whereas $\mathrm{V}_{\text {cyt }}$ had nearly no change. When AP was inhibited by SHAM under $\mathrm{Cd}$ stress, $\mathrm{V}_{\text {alt }}$ was decreased to nearly the control level, and $\mathrm{V}_{\text {cyt }}$ still had little change (Figure 6B). It is worth mentioning that when AP was blocked under Cd stress, applying SNP did not reverse the trend. To further decipher whether the increase of AP in Cd-stressed roots occurs at the protein level, the AOX protein level was detected. Western blotting results showed that Cd stress excited the AOX protein expression in two barley varieties, and the expression of AOX protein was 
higher in Kunlun14 than in Ganpi6. SNP treatment further enhanced the AOX protein levels in both Ganpi6 and Kunlun14 under Cd stress. However, AOX protein amount was markedly reduced when AP was inhibited by SHAM under Cd stress, and even exogenous SNP did not recover the reduction (Figure 6C).

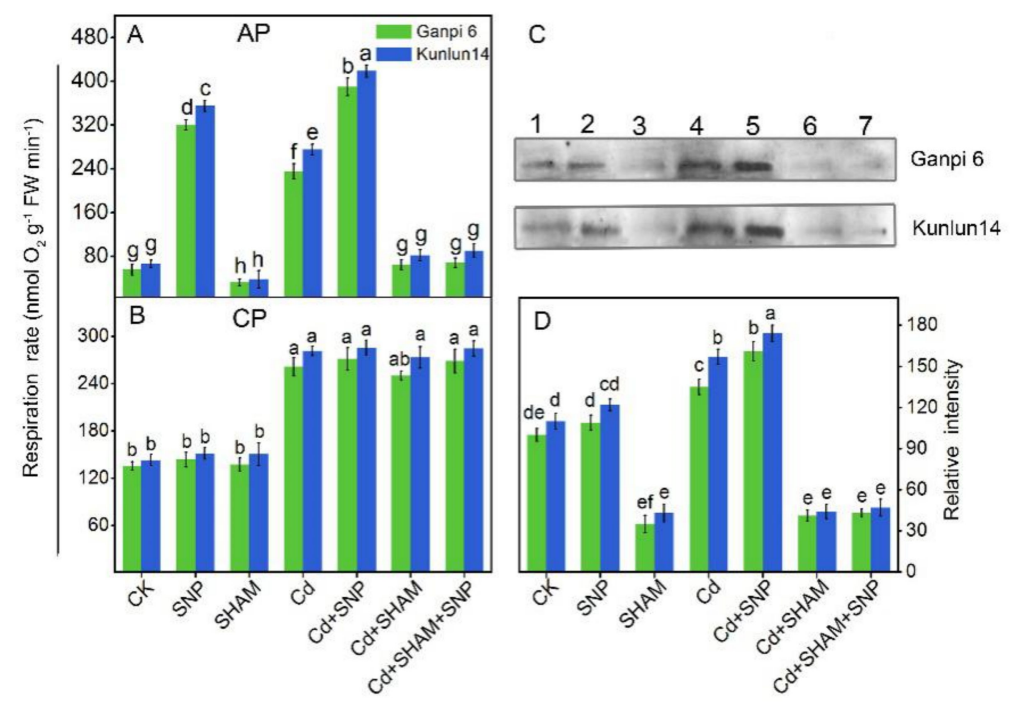

Figure 6. Effects of SNP on alternative pathway capacity $\left(\mathrm{V}_{\mathrm{alt}}\right)(\mathrm{A})$, cytochrome pathway capacity $\left(\mathrm{V}_{\text {cyt }}\right)($ B), western blot analysis (C), and quantification (D) of alternative oxidase (AOX) protein in the roots of Ganpi6 and Kunlun14 under Cd stress. In the experiment, $150 \mu \mathrm{M} \mathrm{Cd}, 150 \mu \mathrm{M}$ SNP, and $100 \mu \mathrm{M}$ SHAM were used. The lane numbers in $(\mathbf{C})$ represent different treatments (Lane 1, CK; 2, SNP; 3, SHAM; 4, Cd; 5, Cd + SNP; 6, Cd + SHAM; 7, Cd + SHAM + SNP). Bars represent mean \pm SE $(n=3)$, and different lower case letters represent significant difference at $p<0.05$.

\subsection{Exogenous NO Did Not Relieve Cd-Induced Oxidative Stress under SHAM Treatment}

To explore whether AP is engaged in Cd-induced oxidative damage in two barley varieties, MDA and EL levels were examined. The MDA content in Ganpi6 and Kunlun14 was increased by $78.7 \%$ and $62.2 \%$, respectively, whereas the EL level was increased by $60.7 \%$ and $50.2 \%$, respectively. Applying SNP greatly relieved the oxidative damage caused by Cd. The MDA content was decreased by $60.3 \%$ and 57.2\% in Ganpi6 and Kunlun14, respectively, whereas EL was decreased by 33.4\% and 30.7\%, respectively (Figure 7C,D). Under Cd + SHAM treatment, the MDA content was increased by 38.6\% and 33.5\% in Ganpi6 and Kunlun14, respectively, whereas EL was increased by 29.5\% and 26.3\%, respectively, and the increases of MDA and EL were not reversed by SNP (Figure 7C,D). Because Cd-induced oxidative damage might be triggered by ROS accumulation, $\mathrm{H}_{2} \mathrm{O}_{2}$ and $\mathrm{O}_{2}{ }^{-}$levels were examined by histochemical staining. As shown in Figure $7 \mathrm{~A}, \mathrm{~B}, \mathrm{H}_{2} \mathrm{O}_{2}$ staining was increased by 3.6 times and 2.8 times, and $\mathrm{O}_{2}{ }^{-}$staining was increased by 3.2 times and 2.1 times in Ganpi6 and Kunlun14 roots under Cd stress, respectively. Applying SHAM further increased the $\mathrm{H}_{2} \mathrm{O}_{2}$ and $\mathrm{O}_{2}{ }^{-}$ staining under Cd stress, which was not attenuated by SNP treatment. The above results suggest that AP plays an indispensable role in NO relief of $\mathrm{Cd}$-induced oxidative stress. 

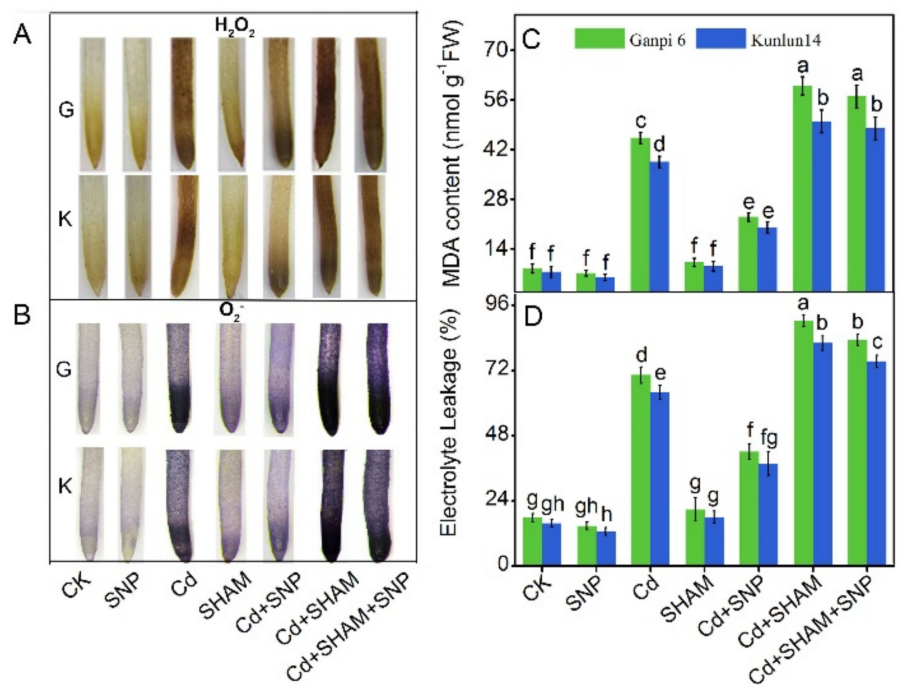

Figure 7. Effects of SNP and SHAM on $\mathrm{H}_{2} \mathrm{O}_{2}(\mathbf{A})$ and $\mathrm{O}_{2}{ }^{-}$(B) accumulation and malonaldehyde (MDA) content (C) and electrolyte leakage (EL) (D) under Cd stress for $48 \mathrm{~h}$ in Ganpi6 and Kunlun14 roots. Bar $=0.5 \mathrm{~cm}$. In the experiment, $150 \mu \mathrm{M} \mathrm{Cd}, 150 \mu \mathrm{M}$ SNP, and $100 \mu \mathrm{M}$ SHAM were used. CK represented the untreated roots of Ganpi6 and Kunlun14. Bars represent mean $\pm \mathrm{SE}(n=3)$ and different lower case letters represent significant difference at $p<0.05$.

\subsection{Effects of Exogenous NO on AsA and GSH Levels in the Presence of SHAM under Cd Stress}

To elucidate the role of AP in controlling ROS homeostasis, the levels of small antioxidant molecules were examined. In Ganpi6 and Kunlun14 roots, an increment in the AsA level (0.8 times and 1.3 times, respectively), a decrease in the DHA level (15.2\% and $15.5 \%$, respectively), and an increase in the AsA/DHA ratio (1.2 times and 1.6 times, respectively) were observed under Cd stress. Applying SNP under Cd stress elevated the AsA level by $23.0 \%$ and $28.2 \%$, and AsA/DHA ratio by $11.8 \%$ and $39.4 \%$ in Ganpi6 and Kunlun14 roots, respectively. However, the presence of SHAM, Cd, or Cd + SNP treatment had almost no impact on AsA or DHA levels in Ganpi6 and Kunlun14 roots (Figure 8A,B). The GSH level was elevated by $37.9 \%$ and $49.6 \%$ in Ganpi6 and Kunlun14 roots, respectively, whereas the GSSG level was decreased by $13.3 \%$ and $12.9 \%$, respectively, and the GSH/GSSG ratio was increased by $49.6 \%$ and $72.0 \%$, respectively. Applying SNP under Cd stress enhanced the GSH level by $10.9 \%$ and $12.1 \%$, lowered the GSSG level by $33.3 \%$ and $38.7 \%$, and elevated the GSH/GSSG ratio by $47.6 \%$ and $54.0 \%$ in Ganpi6 and Kunlun14 roots, respectively. Under Cd + SNP treatment, applying SHAM almost had no effects on GSH or GSSG levels in Ganpi6 and Kunlun14 roots (Figure 8D,E).

To further explore the mechanism of redox balance maintenance, activities of ascorbate-glutathione cycle-related enzymes were examined. Under Cd stress, the activities of GR was increased by $78.6 \%$ and $86.8 \%$, MDHAR was increased by $28.9 \%$ and $34.3 \%$, GPX was increased by $61.3 \%$ and $64.3 \%$, and DHAR was increased by $38.4 \%$ and $39.7 \%$ in Ganpi6 and Kunlun14 roots, respectively. Under Cd + SNP treatment, the activities of GR and MDHAR were further enhanced, whereas the activities of GPX and DHAR were reduced in Ganpi6 and Kunlun14 roots. Under Cd + SNP + SHAM treatment, the activities of these enzymes were nearly undisturbed (Figure $9 \mathrm{E}-\mathrm{H}$ ). These results suggest that AP involvement in SNP-improved tolerance is not achieved by influencing the ascorbate-glutathione cycle. 


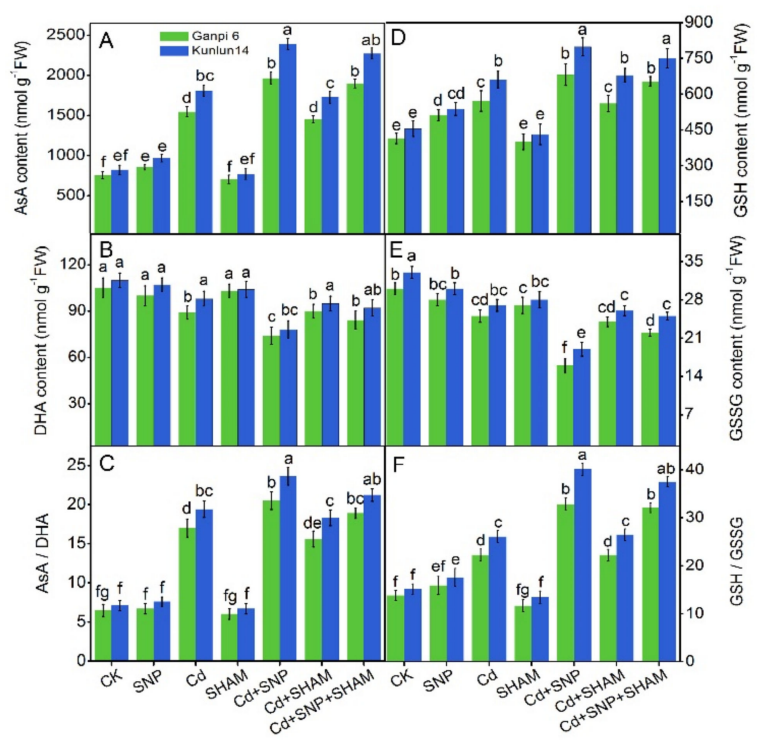

Figure 8. Effects of SNP and SHAM on ascorbic acid (AsA) (A), hydroascorbic acid (DHA) (B), AsA/DHA (C), reduced glutathione (GSH) (D), oxidized glutathione (GSSG) (E), and GSH/GSSG (F) under Cd stress for $48 \mathrm{~h}$. In the experiment, $150 \mu \mathrm{M} \mathrm{Cd}, 150 \mu \mathrm{M}$ SNP, and $100 \mu \mathrm{M}$ SHAM were used. Bars represent mean $\pm \mathrm{SE}(n=3)$, and different lower case letters represent significant difference at $p<0.05$.

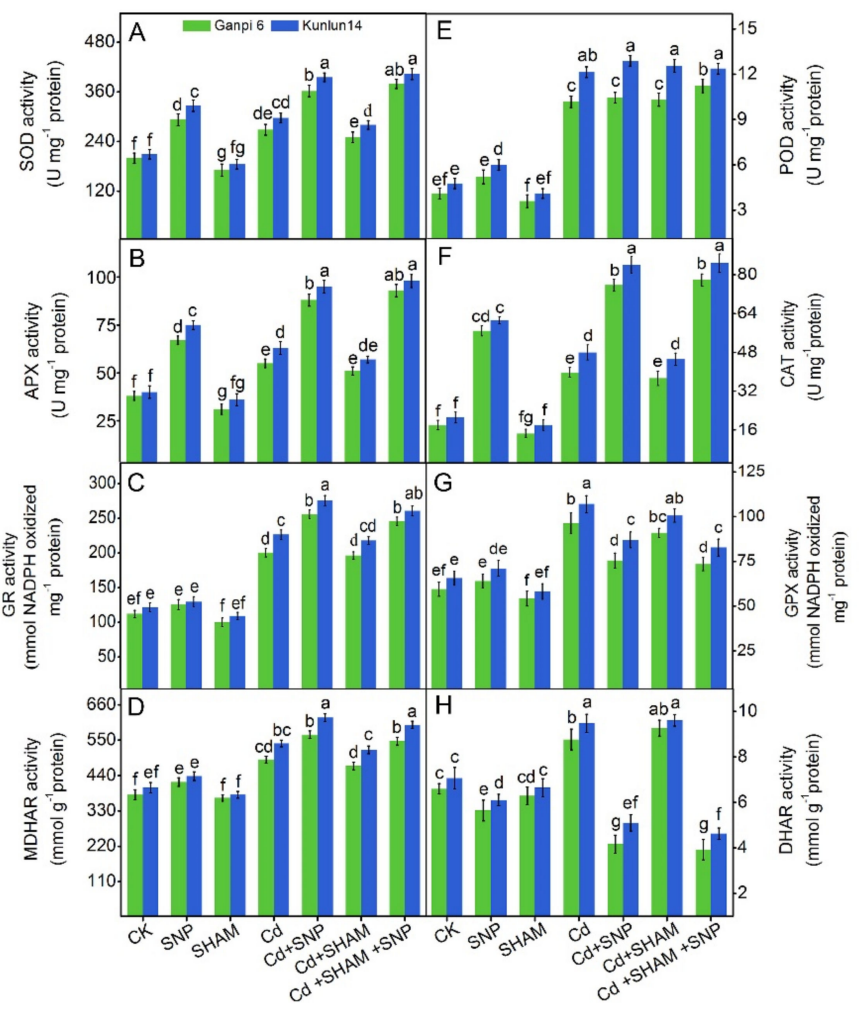

Figure 9. Effects of SNP and SHAM on the enzyme activities of (A) superoxide dismutase (SOD), (B) ascorbate peroxidase (APX), (C) glutathione reductase (GR), (D) monodehydroascorbic acid reductase (MDHAR), (E) peroxidase (POD), (F) catalase (CAT), (G) glutathione peroxidase (GPX), and (H) didehydroascorbic acid reductase (DHAR) under Cd stress for $48 \mathrm{~h}$ in Ganpi6 and Kunlun14 roots. In the experiment, $150 \mu \mathrm{M} \mathrm{Cd}, 150 \mu \mathrm{M}$ SNP, and $100 \mu \mathrm{M}$ SHAM were used. Bars represent mean $\pm \mathrm{SE}$ $(\mathrm{n}=3)$ and different lower case letters represent significant difference at $p<0.05$. 


\subsection{Effects of Exogenous NO on Antioxidant Enzymes in the Presence of SHAM under Cd Stress}

The antioxidant enzyme activities were enhanced under various stresses to reduce the level of ROS [36,42]. As shown in Figure 9A-D, under Cd stress, SOD activity was elevated by $28.6 \%$ and $35.8 \%$, CAT activity by $50.4 \%$ and $56.7 \%$, and POD activity by 1.5 times and 1.7 times in Ganpi6 and Kunlun14, respectively. Under Cd + SNP treatment, activities of all these enzymes (except POD) were further increased in Ganpi6 and Kunlun14 roots. Nevertheless, applying SHAM had nearly no distinct impact on these antioxidant enzymes under Cd + SNP treatment. These results suggest that AP involvement in SNP-improved Cd tolerance in Ganpi6 and Kunlun14 is not achieved by affecting the antioxidant enzyme system (Figure 9A-D).

\section{Discussion}

In this study, we examined the responses of barley (Ganpi6) and highland barley (Kunlun14) to Cd stress, and further explored the possible function of the AOX pathway (AP) in NO-enhanced tolerance to $\mathrm{Cd}$ stress. The results suggest that AP is involved in NO-enhanced tolerance to $\mathrm{Cd}$ stress in barley roots by controlling ROS accumulation.

Oxidative stress is considered as one of important responses to Cd toxicity [56,57]. In our experiment, we observed that the dry weight and the root growth were markedly decreased. However, EL and MDA were obviously increased in two varieties with increased Cd concentration (Figure 1). As a result, $\mathrm{Cd}$ stress induced serious oxidative damage in two varieties.

How Cd activates AP is largely unknown in plants. Recently, some reports suggest that NO could relieve heavy metal toxicity $[14,15,51]$. In this study, to explore the role of NO in regulating AP under $\mathrm{Cd}$ stress in two barley roots, NO donor (SNP) and scavenger (PTIO) were used. Results indicate that NO plays an important role in response to Cd stress. When AP was inhibited under Cd stress, NO fluorescence signal was enhanced (Figure 3), implying that NO and AP have a close relationship in response to $\mathrm{Cd}$ stress. Recently, research has reported that $\mathrm{NO}$ ameliorates arsenic toxicity by altering the alternative oxidase (Aox1) gene expression in Hordeum vulgare L [58]. Applying exogenous SNP relieved Cd-induced oxidative stress in Ganpi6 and Kunlun14 roots. However, when AP was inhibited by SHAM, Cd-induced oxidative stress was further aggravated and it was not reversible by application of SNP (Figure 7), suggesting AP plays an indispensable role in response to Cd stress and participates in the SNP-improved Cd stress tolerance. This is perhaps another crucial reason for the enhanced $\mathrm{Cd}$ tolerance in two barley roots. When AP was inhibited by SHAM under Cd stress, there was nearly no effect on Cd content in two barley shoots or roots (Figure S1), suggesting that AP is not involved in enhancing $\mathrm{Cd}$ tolerance by decreasing $\mathrm{Cd}$ uptake or increasing discharge of $\mathrm{Cd}$. In addition, $\mathrm{Cd}$ content in two barley shoots was minor compared with $\mathrm{Cd}$ content in roots. Therefore, inhibition of $\mathrm{Cd}$ transport from root to stem could be one of the reasons for the tolerance of barley to $\mathrm{Cd}$ stress. We further observed that Cd-induced NO mainly resulted from the NR pathway, which is consistent with some earlier reports [59-61]. Some studies have demonstrated that NOS-regulated NO production is engaged in salt stress and zinc tolerance [21,62], and another report revealed that NO production results from both NR- and NOS-depended pathways [60]. The different source of NO production might be due to various stresses and plant species.

Antioxidant molecules and antioxidant defense system are core elements in keeping ROS homeostasis in barley plants exposed to various stressors [63-65]. Applying SNP could stimulate the antioxidant defense system to enable plant tolerance to stressors $[37,66,67]$. Substantial evidence showed that AOX functions in maintaining ROS homeostasis [33]. A lack of AOX results in elevated activity of ROS-related scavenging enzymes in some plants [48,68]. In this study, we found that the activities of ROS-related scavenging enzymes and antioxidant molecules were enhanced in two barley roots under normal and stressed conditions in the presence of SNP, which is in line with the previous study in barley seedlings [64]. The results also showed that SHAM had nearly no effects on ROS-related scavenging enzymes and antioxidant molecules (Figures 8 and 9). Furthermore, the results showed that the correlation between AP and ROS-related scavenging enzymes or antioxidant molecules was 
minor (Table S1), suggesting that AP engagement in SNP-elevated tolerance is not achieved by affecting ROS-related scavenging enzymes and antioxidant molecules. This observation is different from some previous studies [33,34], possibly due to different stress types and intensity. These results indicated that the elevated ROS-related scavenging enzymes and antioxidant molecules might also be in charge of NO-enhanced tolerance to $\mathrm{Cd}$ stress in two barley varieties.

\section{Conclusions}

On the basis of these results, a signal pathway model was proposed (Figure 10). It illustrates the physiological and biochemical mechanisms of the specific role of AOX pathway involvement in the NO-mediated $\mathrm{Cd}$ tolerance in two barley varieties. NO, which is mainly derived from the NR pathway, is stimulated in response to $\mathrm{Cd}$ stress. $\mathrm{NO}$ acts as a signal molecule to affect the expression of $\mathrm{HvAOX1a}$, $H v A O X 1 d 1$, and $H v A O X 1 d 2$; corresponding AOX proteins; and ultimately $\mathrm{V}_{\text {alt }}$. NO inhibited the ROS burst by promoting AP and ROS-related scavenging enzymes and antioxidant molecules. There was no correlation between AP and antioxidant enzymes or the ascorbate-glutathione cycle in response to $\mathrm{Cd}$ stress. Heavy metal tolerance requires an integrated physiological and biochemical processes. In our study, we prove that the AOX pathway plays an indispensable role in the SNP-elevated resistance to $\mathrm{Cd}$ stress in barley roots. However, it is worth noting that the capacity of AP is not the actual activity of AP $[69,70]$. Measurements of the AP activity in vivo should be done in future because it is crucial for determining the role of AOX in plants.

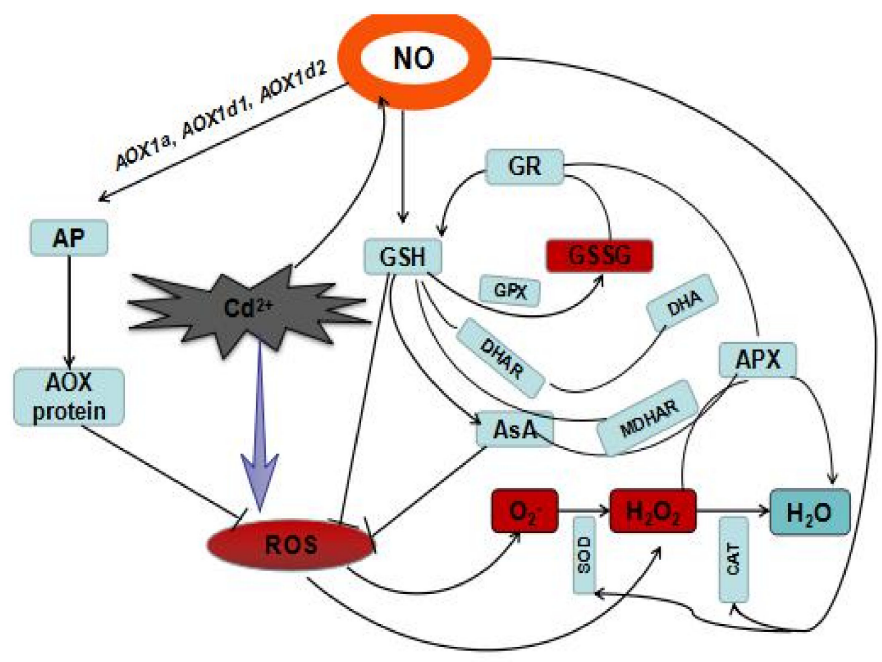

Figure 10. A diagram depicting the $\mathrm{Cd}$-induced toxicity and the protective mechanism in barley roots. Arrows represent the enhanced effects and hyphens represent the suppressed effects.

Supplementary Materials: The following are available online at http://www.mdpi.com/2223-7747/8/12/557/s1, Figure S1: Effect of SHAM on Cd content in shoots (A) and roots (B) of two barley varieties under Cd Stress; Table S1:Correlation coefficient between AP and the enzymatic activities, GSH, ASA, DHA, GSSG, NR, NOS in two barley roots.

Author Contributions: Y.B. and X.W. conceived the project and designed this work; L.H. and R.F. searched the material and write the manuscript; L.H., Q.H., S.W., L.Y., and C.L. participated in the experiments. All authors read and approved the final manuscript.

Funding: This study was supported by the National Natural Science Foundation of China $(31671595 ; 31670244)$, the Agricultural Biotechnology Research and Application Development Program of Gansu Province (GNSW-2016-23), the Project of Qinghai Science and Technology Department (2016-ZJ-Y01), the Open Project of State Key Laboratory of Plateau Ecology and Agriculture, Qinghai University (201-KF-05), and Fundamental Research Funds for the Central Universities (lzujbky-2019-bt05).

Conflicts of Interest: The authors declare no conflict of interest. 


\section{References}

1. Liu, S.; Yang, R.; Pan, Y.; Ma, M.; Pan, J.; Zhao, Y.; Cheng, Q.; Wu, M.; Wang, M.; Zhang, L. Nitric oxide contributes to minerals absorption, proton pumps and hormone equilibrium under cadmium excess in Trifolium repens L. plants. Ecotoxicol. Environ. Saf. 2015, 119, 35-46. [CrossRef] [PubMed]

2. Li, S.W.; Sun, H.J.; Li, H.B.; Luo, J.; Ma, L.Q. Assessment of cadmium bioaccessibility to predict its bioavailability in contaminated soils. Environ. Int. 2016, 94, 600-606. [CrossRef] [PubMed]

3. Ortega-Villasante, C.; Rellán-Álvarez, R.; Del Campo, F.; Carpena-Ruiz, O.; Hernández, L.E. Cellular damage induced by cadmium and mercury in Medicago sativa. J. Exp. Bot. 2005, 56, 2239-2251. [CrossRef]

4. Sharma, S.S.; Dietz, K.J.; Mimura, T. Vacuolar compartmentalization as indispensable component of heavy metal detoxification in plants. Plant Cell Environ. 2016, 39, 1112-1126. [CrossRef] [PubMed]

5. Wang, J.L.; Li, T.; Liu, G.Y.; Smith, J.M.; Zhao, Z.W. Unraveling the role of dark septate endophyte (DSE) colonizing maize (Zea mays L.) under cadmium stress: Physiological, cytological and genic aspects. Sci. Rep. 2016, 6, 22028. [CrossRef] [PubMed]

6. Elobeid, M.; Gobel, C.; Feussner, I.; Polle, A. Cadmium interferes with auxin physiology and lignification in poplar. J. Exp. Bot. 2012, 63, 1413-1421. [CrossRef]

7. Qin, W.; Bazeille, N.; Henry, E.; Zhang, B.; Deprez, E. Mechanistic insight into cadmium-induced inactivation of the bloom protein. Sci. Rep. 2016, 6, 26225. [CrossRef]

8. Kopyra, M.; Stachoń-Wilk, M.; Gwóźdź, E.A. Effects of exogenous nitric oxide on the antioxidant capacity of cadmium-treated soybean cell suspension. Acta Physiol. Plant. 2006, 28, 525-536. [CrossRef]

9. Semane, B.; Cuypers, A.; Smeets, K.; Van Belleghem, F.; Horemans, N.; Schat, H.; Vangronsveld, J. Cadmium responses in Arabidopsis thaliana: Glutathione metabolism and antioxidative defence system. Physiol. Plant. 2007, 129, 519-528. [CrossRef]

10. Stohs, S.J.; Bagchi, D. Oxidative mechanisms in the toxicity of metal ions. Free Radic. Biol. Med. 1995, 18, 321-336. [CrossRef]

11. Siddiqui, M.H.; Al-Whaibi, M.H.; Basalah, M.O. Role of nitric oxide in tolerance of plants to abiotic stress. Protoplasma 2011, 248, 447-455. [CrossRef] [PubMed]

12. Mur, L.; Mandon, J.; Persijn, S.; Cristescu, S.M.; Moshkov, I.E.; Novikova, G.V.; Hall, M.A.; Harren, F.J.M.; Hebelstrup, K.H.; Gupta, K.J. Nitric oxide in plants: An assessment of the current state of knowledge. $A o B$ Plants 2013, 5, 124-137. [CrossRef] [PubMed]

13. Asgher, M.; Per, T.S.; Masood, A.; Fatma, M.; Freschi, L.; Corpas, F.J.; Khan, N.A. Nitric oxide signaling and its crosstalk with other plant growth regulators in plant responses to abiotic stress. Environ. Sci. Pollut. Res. 2017, 24, 2273-2285. [CrossRef] [PubMed]

14. Domingos, P.; Prado, A.M.; Wong, A.; Gehring, C.; Feijo, J.A. Nitric oxide: Amultitasked signaling gas in plants. Mol. Plant 2015, 8, 506-520. [CrossRef]

15. Wang, D.; Liu, Y.; Tan, X.; Liu, H.; Zeng, G.; Hu, X.; Jian, H.; Gu, Y. Effect of exogenous nitric oxide on antioxidative system and S-nitrosylation in leaves of Boehmeria nivea (L.) Gaud under cadmium stress. Environ. Sci. Pollut. Res. Int. 2015, 22, 3489-3497. [CrossRef]

16. Barroso, J.B.; Corpas, F.J.; Carreras, A.; Rodriguez-Serrano, M.; Esteban, F.J.; Fernandez-Ocana, A.; Chaki, M.; Romero, M.C.; Valderrama, R.; Sandalio, L.M. Localization of S-nitrosoglutathione and expression of S-nitrosoglutathione reductase in pea plants under cadmium stress. J. Exp. Bot. 2006, 57, 1785-1793. [CrossRef]

17. Corpas, F.J.; Barroso, J.B.; Palma, J.M.; Rodriguez-Ruiz, M. Plant peroxisomes: A nitro-oxidative cocktail. Redox Biol. 2017, 11, 535-542. [CrossRef]

18. Laemmli, U.K. Cleavage of structural proteins during the assembly of the head of bacteriophage T4. Nature 1970, 227, 680-685. [CrossRef]

19. Wang, L.N.; Yang, L.M.; Yang, G.J.; Li, X.G.; Song, Y.P.; Wang, X.F.; Hu, X.Y. Involvements of $\mathrm{H}_{2} \mathrm{O}_{2}$ and metallothionein in NO-mediated tomato tolerance to copper toxicity. J. Plant Physiol. 2010, 167, 1298-1306. [CrossRef]

20. Panda, P.; Nath, S.; Chanu, T.T.; Sharma, G.D.; Panda, S.K. Cadmium stress-induced oxidative stress and role of nitric oxide in rice (Oryza sativa L.). Acta Physiol. Plant. 2011, 33, 1737-1747. [CrossRef] 
21. Xu, J.; Wang, W.; Yin, H.; Liu, X.; Sun, H.; Mi, Q. Exogenous nitric oxide improves antioxidative capacity and reduces auxin degradation in roots of Medicago truncatula seedlings under cadmium stress. Plant Soil 2010, 326, 321-330. [CrossRef]

22. Xu, J.; Wang, W.; Sun, J.; Zhang, Y.; Ge, Q.; Du, L.; Yin, H.; Liu, X. Involvement of auxin and nitric oxide in plant Cd-stress responses. Plant Soil 2011, 346, 107-119. [CrossRef]

23. Fan, S.K.; Fang, X.Z.; Guan, M.Y.; Ye, Y.Q.; Lin, X.Y.; Du, S.T.; Jin, C.W. Exogenous abscisic acid application decreases cadmium accumulation in Arabidopsis plants, which is associated with the inhibition of IRT1-mediated cadmium uptake. Front. Plant Sci. 2014, 5, 721. [CrossRef] [PubMed]

24. Wang, Q.; Liang, X.; Dong, Y.; Xu, L.; Zhang, X.; Kong, J.; Liu, J. Effects of exogenous salicylic acid and nitric oxide on physiological characteristics of perennial ryegrass under cadmium stress. J. Plant Growth Regul. 2013, 32, 721-731. [CrossRef]

25. Zhang, L.; Chen, Z.; Zhu, C. Endogenous nitric oxide mediates alleviation of cadmium toxicity induced by calcium in rice seedlings. J. Environ. Sci. 2012, 24, 940-948. [CrossRef]

26. Shi, H.; Ye, T.; Chan, Z. Nitric oxide-activated hydrogen sulfide is essential for cadmium stress response in bermudagrass (Cynodon dactylon (L). Pers.). Plant Physiol. Biochem. 2014, 74, 99-107. [CrossRef]

27. Gill, M.; Hasanuzzaman, K.; Nahar, A.; Macovei, N.; Tuteja, N. Importance of nitric oxide in cadmium stress tolerance in crop plants. Plant Physiol. Biochem. 2012, 63, 254-261. [CrossRef]

28. Vanlerberghe, G.C.; Day, D.A.; Wiskich, J.T.; Vanlerberghe, A.E.; McIntosh, L. AOX activity in tobacco leaf mitochondria: Dependence on tricarboxylic acid cycle-mediated redox regulation and pyruvate activation. Plant Physiol. 1995, 109, 353-361. [CrossRef]

29. Király, L.; Hafez, Y.; Fodor, J.; Király, Z. Suppression of tobacco mosaic virus-induced hypersensitive-type necrotization in tobacco at high temperature is associated with downregulation of NADPH oxidase and superoxide and stimulation of dehydroascorbate reductase. J. Gen. Virol. 2008, 89, 799-808. [CrossRef]

30. Watanabe, C.K.; Hachiya, T.; Terashima, I.; Noguchi, K. The lack of alternative oxidase at low temperature leads to a disruption of the balance in carbon and nitrogen metabolism, and to an up-regulation of antioxidant defence systems in Arabidopsis thaliana leaves. Plant Cell Environ. 2008, 31, 1190-1202. [CrossRef]

31. Wang, F.; Wang, X.M.; Zhao, C.Z.; Wang, J.F.; Li, P.; Dou, Y.Q.; Bi, Y.R. Alternative pathway is involved in the tolerance of highland barley to the low-nitrogen stress by maintaining the cellular redox homeostasis. Plant Cell Rep. 2016, 35, 317-328. [CrossRef]

32. Uraguchi, S.; Fujiwara, T. Cadmium transport and tolerance in rice: Perspectives for reducing grain cadmium accumulation. Rice 2012, 27, 5. [CrossRef]

33. Vanlerberghe, G.C. Alternative oxidase: A mitochondrial respiratory pathway to maintain metabolic and signaling homeostasis during abiotic and biotic stress in plants. Int. J. Mol. Sci. 2013, 14, 6805-6847. [CrossRef]

34. Jia, H.L.; Wang, X.F.; Dou, Y.H.; Liu, D.; Si, W.T.; Fang, H.; Zhao, C.; Chen, S.L.; Xi, J.J.; Li, J.S. Hydrogen sulfide-cysteine cycle system enhances cadmium tolerance through alleviating cadmium-induced oxidative stress and ion toxicity in Arabidopsis roots. Sci. Rep. 2016, 6, 39702. [CrossRef]

35. Fu, L.J.; Shi, K.; Gu, M.; Zhou, Y.H.; Dong, D.K.; Liang, W.S.; Song, F.M.; Yu, J.Q. Systemic induction and role of mitochondrial alternative oxidase and nitric oxide in a compatible tomato-Tobacco mosaic virus interaction. Mol. Plant Microbe Interact. 2010, 23, 39-48. [CrossRef]

36. Jian, W.; Zhang, D.W.; Zhu, F.; Wang, S.X.; Pu, X.J.; Deng, X.G.; Luo, S.S.; Lin, H.H. Alternative oxidase pathway is involved in the exogenous SNP-elevated tolerance of Medicago truncatula to salt stress. J. Plant Physiol. 2016, 193, 79-87. [CrossRef]

37. Aftab, T.; Khan, M.M.A.; Naeem, M.; Idrees, M.; da Silva, J.A.T.; Ram, M. Exogenous nitric oxide donor protec ts Artemisia annua from oxidative stress generated by boron and aluminium toxicity. Ecotoxicol. Environ. Saf. 2012, 80, 60-68. [CrossRef]

38. Huang, X.; Rad, U.; Durner, J. Nitric oxide induces transcriptional activation of the nitric oxide-tolerant alternative oxidase in Arabidopsis suspension cells. Planta 2002, 215, 914-923. [CrossRef]

39. Ederli, L.; Morettini, R.; Borgogni, A.; Wasternack, C.; Miersch, O.; Reale, L.; Ferranti, F.; Tosti, N.; Pasqualini, S. Interaction between nitric oxide and ethylene in the induction of alternative oxidase in ozone-treated tobacco Plants. Plant Physiol. 2006, 142, 595-608. [CrossRef]

40. Siddiqi, M.Y.; Glass, A.D.M.; Ruth, T.J.; Fernando, M. Studies of the regulation of nitrate influx by barley seedlings using (No3-1)-N-13. Plant Physiol. 1989, 90, 806-813. [CrossRef] 
41. Tang, H.; Zhang, D.W.; Yuan, S.; Zhu, F.; Xu, F.; Fu, F.Q.; Wang, S.X.; Lin, H.H. Plastid signals induce alternative oxidase expression to enhance the cold stress tolerance in Arabidopsis thaliana. Plant Growth Regul. 2014, 74, 275-283. [CrossRef]

42. Wang, H.H.; Huang, J.J.; Liang, X.L.; Bi, Y.R. Involvement of hydrogen peroxide, calcium, and ethylene in the induction of the alternative pathway in chilling-stressed Arabidopsis callus. Planta 2012, 235, 53-67. [CrossRef]

43. Wang, X.M.; Chang, N.; Bi, Y.R.; Tan, B.C. Measurement of mitochondrial respiration rate in maize (Zea mays L.) leaves. Bio Protocol 2015, 5, e1483. [CrossRef]

44. Mackintosh, C.; Douglas, P.; Lillo, C. Identification of protein that inhibits the phosphorylated form of nitrate reductase from spinach (Spinacia oleracea) leaves. Plant Physiol. 1995, 107, 451-457. [CrossRef]

45. Lin, A.H.; Wang, Y.Q.; Tang, J.Y.; Xue, P.; Li, C.L.; Liu, L.C.; Hu, B.; Yang, F.Q.; Loake, G.J.; Chu, C.C. Nitric oxide and protein S-nitrosylation are integral to hydrogen peroxide-induced leaf cell death in rice. Plant Physiol. 2012, 158, 451-464. [CrossRef]

46. Zhao, C.Z.; Wang, X.M.; Wang, X.Y.; Wu, K.L.; Li, P.; Chang, N.; Wang, J.F.; Wang, F.; Li, J.L.; Bi, Y.R. Glucose-6-phosphate dehydrogenase and alternative oxidase are involved in the cross tolerance of highland barley to salt stress and UV-B radiation. J. Plant Physiol. 2015, 181, 83-95. [CrossRef]

47. Wang, H.H.; Hou, J.J.; Li, Y.; Zhang, Y.Y.; Huang, J.J.; Liang, W.H. Nitric oxide-mediated cytosolic glucose-6-phosphate dehydrogenase is involved in aluminum toxicity of soybean under high aluminum concentration. Plant Soil 2017, 416, 39-52. [CrossRef]

48. Giraud, E.; Ho, L.H.M.; Clifton, R.; Carroll, A.; Estavillo, G.; Tan, Y.F.; Howell, K.A.; Ivanova, A.; Pogson, B.J.; Millar, A.H.; et al. The absence of alternative oxidase1a in Arabidopsis results in acute sensitivity to combined light and drought stress. Plant Physiol. 2008, 147, 595-610. [CrossRef]

49. Zhang, F.Q.; Zhang, H.X.; Wang, G.P.; Xu, L.L.; Shen, Z.G. Cadmium-induced accumulation of hydrogen peroxide in the leaf apoplast of Phaseolus aureus and Vicia sativa and the roles of different antioxidant enzymes. J. Hazard. Mater. 2009, 168, 76-84. [CrossRef]

50. Perez-Chaca, M.V.; Rodriguez-Serrano, M.; Molina, A.S.; Pedranzani, H.E.; Zirulnik, F.; Sandalio, L.M.; Romero-Puertas, M.C. Cadmium induces two waves of reactive oxygen species in Glycine max (L.) roots. Plant Cell Environ. 2014, 37, 1672-1681. [CrossRef]

51. Liu, S.L.; Yang, R.J.; Tripathi, D.K.; Li, X.; Jiang, M.Y.; Lv, B.Y.; Ma, M.D.; Chen, Q.B. Signalling cross-talk between nitric oxide and active oxygen in Trifolium repens L. plants responses to cadmium stress. Environ. Pollut. 2018, 239, 53-68. [CrossRef]

52. Planchet, E.; Gupta, K.J.; Sonoda, M.; Kaiser, W.M. Nitric oxide emission from tobacco leaves and cell suspensions: Rate limiting factors and evidence for the involvement of mitochondrial electron transport. Plant J. 2005, 41, 732-743. [CrossRef]

53. Gupta, K.J.; Fernie, A.R.; Kaiser, W.M.; Dongen, J.T. On the origins of nitric oxide. Trends Plant Sci. 2010, 16, 160-168. [CrossRef]

54. Cvetkovska, M.; Vanlerberghe, G.C. Alternative oxidase impacts the plant response to biotic stress by influencing the mitochondrial generation of reactive oxygen species. Plant Cell Environ. 2013, 36, 721-732. [CrossRef]

55. Wanniarachchi, V.; Dametto, L.; Sweetman, C.; Shavrukov, Y.; Day, D.; Jenkins, C.; Soole, K. Alternative respiratory pathway component genes(AOX and ND) in rice and barley and their response to stress. Int. J. Mol. Sci. 2018, 19, 915. [CrossRef]

56. Feng, H.Q.; Li, X.; Duan, J.G.; Li, H.Y.; Liang, H.G. Chilling tolerance of wheat seedlings is related to an enhanced alternative respiratory pathway. Crop Sci. 2008, 48, 2381-2388. [CrossRef]

57. Cvetkovska, M.; Vanlerberghe, G.C. Alternative oxidase modulates leaf mitochondrial concentrations of superoxide and nitric oxide. New Phytol. 2012, 195, 32-39. [CrossRef]

58. Shukla, P.; Singh, S.; Dubey, P.; Singh, A.; Singh, A.K. Nitric oxide mediated amelioration of arsenic toxicity which alters the alternative oxidase (Aox1) gene expression in Hordeum vulgare L. Ecotoxicol. Environ. Saf. 2015, 120, 59-65. [CrossRef]

59. Liu, Y.; Wu, R.; Wan, Q.; Xie, G.; Bi, Y. Glucose-6-phosphate dehydrogenase plays a pivotal role in nitric oxide-involved defense against oxidative stress under salt stress in red kidney bean roots. Plant Cell Physiol. 2007, 48, 511-522. [CrossRef] 
60. Zhao, M.G.; Chen, L.; Zhang, L.L.; Zhang, W.H. Nitric reductase dependent nitric oxide production is involved in cold acclimation and freezing tolerance in Arabidopsis. Plant Physiol. 2009, 151, 755-767. [CrossRef]

61. Hu, Y.; You, J.; Liang, X. Nitrate reductase-mediated nitric oxide production is involved in copper tolerance in shoots of hulless barley. Plant Cell Rep. 2015, 34, 367-379. [CrossRef]

62. Zhao, M.G.; Tian, Q.Y.; Zhang, W.H. Nitric oxide synthase dependent nitric oxide production is associated with salt tolerance in Arabidopsis. Plant Physiol. 2007, 144, 206-217. [CrossRef]

63. Peksen, S.; Sanal, F. Arsenic effects on lipid peroxidation and antioxidative enzyme activities in barley cultivars roots. Fresenius Environ. Bull. 2018, 27, 5871-5881.

64. Chen, F.; Wang, F.; Sun, H.Y.; Cai, Y.; Mao, W.H.; Zhang, G.P.; Vincze, E. Genotype-dependent effect of exogenous nitric oxide on Cd-induced changes in antioxidative metabolism, ultrastructure, and photosynthetic performance in barley seedlings (Hordeum vulgare). J. Plant Growth Regul. 2010, 29, 394-408. [CrossRef]

65. Wang, X.J.; Ma, R.N.; Cui, D.J.; Cao, Q.; Shan, Z.; Jiao, Z. Physio-biochemical and molecular mechanism underlying the enhanced heavy metal tolerance in highland barley seedlings pretreated with low-dose gamma irradiation. Sci. Rep. 2017, 7, 14233. [CrossRef]

66. Wang, Z.F.; Li, Q.; Wu, W.G.; Guo, J.; Yang, Y.L. Cadmium stress tolerance in wheat seedlings induced by ascorbic acid was mediated by NO signaling pathways. Ecotoxicol. Environ. Saf. 2017, 135, 75-81. [CrossRef]

67. Qian, H.F.; Chen, W.; Li, J.J.; Wang, J.; Zhou, Z.; Liu, W.P.; Fu, Z.W. The effect of exogenous nitric oxide on alleviating herbicide damage in Chlorella vulgaris. Aquat. Toxicol. 2009, 92, 250-257. [CrossRef]

68. Amirsadeghi, S.; Robson, C.A.; McDonald, A.E.; Vanlerberghe, G.C. Changes in plant mitochondrial electron transport alter cellular levels of reactive oxygen species and susceptibility to cell death signaling molecules. Plant Cell Physiol. 2006, 47, 1509-1519. [CrossRef]

69. Millenaar, F.F.; Gonzalez-Meler, M.A.; Fiorani, F.; Welschen, R.; Ribas-Carbo, M.; Siedow, J.N.; Anneke, M.; Wagner, A.M.; Lambers, H. Regulation of alternative oxidase activity in six wild monocotyledonous species. An in vivo study at the whole root level. Plant Physiol. 2001, 126, 376-387. [CrossRef]

70. Ribas-Carbo, M.; Berry, J.A.; Yakir, D.; Giles, L.; Robinson, S.A.; Lennon, A.M.; Siedow, J.N. Electron Partitioning between the Cytochrome and Alternative Pathways in Plant Mitochondria. Plant Physiol. 1995, 109, 829-837. [CrossRef] 